\title{
OS PADRÖES DE COMPORTAMENTO HUMANO: UMA PROPOSTA DE TRADUÇÃO DOS TERMOS DA TAXONOMIA I SOBRE DIAGNÓSTICOS DE ENFERMAGEM
}

\author{
Isabel Cristina Fonseca da Cruz* \\ Diná de A. L. M. da Cruz**
}

CKUZ, I.C.F. da; CRUZ, D. de A.L.M. da. Os padrões de comportamento humano: unla proposta de tradução dos termos da taxonomia I sobre diagnósticos de enfermagen. Rev. Esc. Enf. USP, v. 25, n. 1, p. 17-20, abr. 1991.

Neste estudo é apresentada uma tradução dos Padrões de Comportamento Humano, refierencial conceptualda Taxonomial da North American Nursing Diagnosis Association.

UNITERMOS: Comportamento humano. Diagnóstico de enfermagem.

\section{INTRODUÇÃO}

O diagnóstico de enfermagem é o julgamento clínico do enfermeiro sobre o seu cliente, para a descrição, de forma concisa, dos problemas de saúde deste, reais ou potenciais, que o profissional tem competência para tratar. No entanto, as dificuldades existentes para a formulação de termos diagnósticos, concisos e válidos, tornaram-se um tema crucial, que levaram à realização de estudos sobre diagnósticos.

A utilização da expressão "diagnóstico de enfermagem" surgiu na literatura na década de 50 e até os anos setenta o seu emprego parece ter sido raro. $\mathrm{Na}$ década de setenta, foi criada nos Estados Unidos uma associação, a "North American Nursing Diagnosis Association" (NANDA), que coordena as pesquisas nesta área (CARPENITO, 1983).

Os trabalhos dessa associação tratam das questões relativas à nomenclatura e à taxonomia dos diagnósticos. Considerando a necessidade de um sistema de referência para se fazer um diagnóstico, que sirva para o julgamento sobre a pertinência e consistência deste diagnóstico para o grupo profissional, assim a relevância dos trabalhos da NANDA (1989) quando se trata de diagnósticos de enfermagem, vemos com

\footnotetext{
* Enfermeira. Mestre em Enfermagern. Professona do Depto. de Enfermagem Medico-Cirúrgica da EEAN-UFRJ. Doutoranda da Escola de Enfermagem da USP - Săo Paulo.

** Enfermeira. Mestre em Enfermagem. Professora Assistente do Depto. de Enfermagem Médico-Cirúrgica da Escola de Enfermagem da USP, Săa Paulo. Doutoranda da Escola de Enfermagem da USP - Săo Paulo.
} 
preocupação a barreira da língua que pode, em nosso meio, levar à inconsistência, gerando desinteresse ou incorreçōes para a validação dos termos já propostos.

Temos conhecimento de que, no Brasil, têm sido feitos alguns trabalhos sobre diagnósticos (CRUZ, 1989; CRUZ, 1990). No nosso entendimento, é de suma importância a uniformização dos termos e expressões utilizados em língua portuguesa, nas traduções dos diagnósticos de enfermagem propostos na Taxonomia I, da NANDA (1989).

Visando contribuir para essa uniformização, apresentamos neste trabalho uma proposta de tradução dos "Padrões de Comportamento Humano" que compõem a estrutura conceitual para a organização dos diagnósticos em uma taxonomia.

\section{Desenvolvimento}

Considerando que os diagnósticos de enfermagem expressam os problemas de saúde do cliente, sejam eles reais ou potenciais, um grupo de teoristas da NANDA preparou as bases estruturais para a taxonomia. Foi criado um referencial de conceitos, com base no comportamento, constituído por nove pađ̄rões de comportamento humano.

Cabe ressaltar que estes conceitos são apresentados concisamente na literatura, o que dificulta a sua compreensão e, por conseguinte, a captação dos reais significados que originalmente a eles foram atribuídos.

Um padrão relaciona-se a tudo aquilo que é utilizado como base para uma avaliação, seja ela quantitativa ou qualitativa. O comportamento, por sua vez, refere-se ao desempenho, atuação, reação ou resposta de uma pessoa, num determinado contexto. A designação "Padrão de Comportamento Humano" é compreendida como o conjunto de atitudes e reações do cliente, em face da doença, que serve de base para um julgamento deliberado ou diagnóstico de Enfermagem.

O primeiro padrão de comportamento humano da Taxonomia é designado pelo termo Troca (exchanging), para o qual atribuimos o seguinte significado: é o padrão de comportamento humano que envolve os sistemas de controle do corpo num processo de permuta com o meio físico, onde ocorre a captação, a transformação e a eliminação de elementos.

O padrão Troca engloba alterações na nutrição, no sistema imunitário e temperatura, nas eliminaçōes, na circulação, na oxigenação e na integridade física.

Outro padrão da Taxonomia I é designado por comunicação (communicating) que, numa tradução literal, significa não só a emissão, como também o recebimento de mensagens. Contudo, na sua definição original, isto é, segundo a Taxonomia I, este padrão descreve o compor- 
tamento referente apenas à transmissão de mensagens. No sentido de aproximar o termo em português do significado pretendido, optamos pela palavra Expressão.

Assim sendo, Expressão refere-se ao padrão de comportamento humano que envolve o envio de mensagens verbais e não-verbais. Sobre a Expressão, temos ainda poucôs diagnósticos nesta área. Vale destacar a importância da realização de estudos de enfermagem sobre a comunicação não-verbal.

Relacionamento (relating) é o padrão de comportamento humano que diz respeito à capacidade de estabelecer vínculos com os semelhantes. Este padrão compreende as alterações que ocorrem na socialização, no desempenho do papel social e da sexualidade.

O termo Valoração (valuing) referc-se ao padrão de comportamento humano que envolve o julgamento sobre o significado ou a importância das coisas, ou seja, daquilo que existe ou pode existir. O significado dos valores é uma área dentro da taxonomia dos diagnósticos que está por ser explicada. No momento, o padrão Valoração inclui apenas a alteração no estado espiritual da pessoa, implicando em preocupação com o processo da morte, a transcendência e o significado das experiências existenciais.

O termo Escolha (choosing) designa o padrão de comportamento humano referente a seleção de alternativas. Nesta circunstância, a pessoa vive um processo no qual levanta e examina soluções para deliberar sobre uma determinada situação. A Escolha engloba as alterações nos processos adaptativo e de participação, tanto individual como familiar ou comunitário. Espera-se que a criação de termos nesta área torne mais nítido o objeto da enfermagem.

A Ativĩdade (moving) trata do padrão de comportamento refierente à capacidade de executar açōes voluntárias. Este padrão relaciona-se com as alterações na mobilidade física e social, no repouso, no lazer, no crescimento e na realização das atividades diárias, sejam elas de manutenção do lar ou de cuidados pessoais.

A Percepção (perceiving) designa o padrão de comportamento humano que envolve a captação de informações através dos órgãos dos sentidos, e a interpretação ou formação de idiéias com base apenas nestas informações. A Percepção engloba tanto as altelaçöes no auto-conceito e no significado da vida, como as alterações nos órgãos do sentido.

O Conhecimento trata do padrão de comportamento humano associado à compreensão racional do significado preciso de uma informação. Este é também um padrão que ainda não foi plenamente explorado; refere-se, contudo, às alterações no conhecimento, na apredizagem e no processo de pensamento.

O Sentimento designa o padrão de comportamento humano que se refere à consciência emocional, subjetiva, de uma informação. Neste 
padrão estão presentes as alteraçōes quanto de conforto e de integridade emocional.

\section{Considerações Finais}

O estudo sobre diagnósticos de enfermagem e da estrutura referencial de uma taxonomia para organizá-los é importante para o desenvolvimento do corpo de conhecimentos da profissão. Com esta tradução sobre os padrões de comportamento, esperamos estimular as discussões a respeito deste tema e contribuir para a compreensão dos termos propostos pela NANDA. O interesse pela realização de estudos sobre diagnósticos, no Brasil, pode favorecer o esclarecimento de questões ainda não resolvidas nesta área, assim como o refinamento da taxonomia proposta.

CRUZ, I.C.F. da; CRUZ, D. de A.L.M. da Human response patterns: a comprehensive translation to portuguese of the taxonomy I. Rev. Esc. Enf. USP, v. 25, n. 1, p. 17-26, apr. 1991.

This study presents a translation to Portuguese of the Human Response Patterns which are conceptual framework of Taxonomyl proposed by North American Nursing Diagnosis Association.

UNITERMS: Behavior. Nursing diagnosis.

\section{REFERENCIAS BIBLIOGRAFICAS}

CARPENito, L.J. Nursing Diagnosis: application to clinical practice. 2. ed. Philadelphia J.B. Lippincott, 1983.

CRUZ, D.A.L.M. da. Diagnósticos de enformagem o padrões funcionais de saúde alterados em pacientes internados por cardiopatia chagásica crônica. Săo Paulo, 1989, 97 p. Dissertação (Mestrado) - Escola de Enfermagem da Universidade de Săo Paulo.

CRUZ, I.C.F́. da. Diagnósticos de enfermagem e sua aplicaçăo: revisão de literatura. kov. Ese. Enf. USP, v. 24, n. 1, p. 149-62, 1990.

NORTH AMERICAN NURSING DIAGNOSIS ASSOCIATION. Taxonomy I revised 1989: with official diagnostic categories. St. Louls, Mosby, 1989.

GUYTON, A.C. Tratado de fislologia médica. 5 ed., Rio de Janeiro, Interamericana, 1977.

MILLER, B.F.; KEANE, C.B. Encyclopedia and dictionary of medicine, nursing and allied health. 4. ed., Philadelphia, Saunders, 1987.

Recebido em 04/07/90 